\title{
Spraying for Longer Periods without Fatigue
}

\section{A newly developed spray gun series for manual electrostatic spraying is very compact and light, thus ensuring fatigue-free working.}

$T$ he new manual electrostatic spray guns from Wagner not only deliver excellent results with regard to surface quality and wraparound, their low weight also makes them the smallest and lightest spray guns in their class. Due to their good balance, they sit perfectly in the hand, ensuring fast and fatigue-free spraying.

The spray guns also allow quick and easy adjustment of all important parameters directly at the gun. Recipes set at the control unit can be selected directly at the gun and activated at the push of a button. This enables operators to quickly change the recipe for optimum coating of each workpiece.

\section{Integrated light signal}

An integrated light signal gives the operator continuous feedback on the current status in order to achieve the required coating finish. If the light changes colour, the operator knows immediately that he should check the working conditions, such as the distance to the workpiece, the process parameters or the grounding of the workpiece. An integrated switch allows the operator to turn the high voltage off directly at the spray gun in order to coat electrostatically difficult areas or for safe flushing.

The spray gun is available as an AirCoat and Airspray model. Both models can be ordered in different versions that

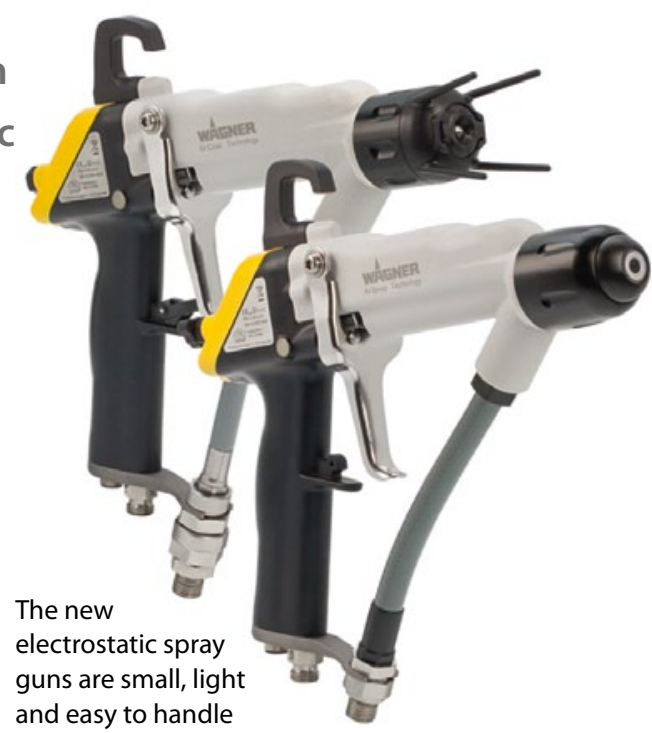

found primarily in their new air caps and nozzles, which provide good atomisation due to the simple regulation of the spray jet depending on the type of material.

The integrated material valve allows the nozzle to be changed quickly and easily without relieving the material pressure and flushing the gun. The needle stroke adjustment ensures that the paint flow can be directly 'fine tuned' with an indexing function.

The AirCoat electrostatic spray guns (GM 5000EAC) provide a soft spray pattern and very high transfer efficiency. There is a wide choice of air caps available for round spray and flat spray for every kind of material, from low to high viscosity.

The newly developed nozzle (ACF 5000) combines a good spray pattern with easy flushing. The integrated material valve makes it possible to change the nozzle without relieving the pressure and without flushing the gun. As a result, the spray gun is ready to use again almost immediately.

In addition, swivel joints on the material and air hose increase handling and manoeuvrability. The spray gun can be moved easily into any position required. The Airspray gun (GM 5000EA) as a 250 bar electrostatic gun can also be used to apply high viscosity materials even with a long hose. The manufacturer also supplies control modules are suitable for solvent-based and waterbased materials and which cover a broad range of applications.

\section{Fast nozzle changes}

The advantages of the Airspray electrostatic spray guns (GM 5000EA) can be
For more information, please contact:

J. Wagner GmbH, Markdorf, Germany, Tel. + 4975 44 5 05-0, wagner@wagner-group.com,www.wagner-group.com 